\title{
Long-term ABA Therapy Is Abusive: A Response to Gorycki, Ruppel, and Zane
}

\author{
Gary Shkedy ${ }^{1}$ - Dalia Shkedy ${ }^{1}$ - Aileen H. Sandoval-Norton ${ }^{1}$ (D)
}

Accepted: 26 March 2021 / Published online: 9 April 2021

(C) The Author(s) 2021, corrected publication 2022

\begin{abstract}
Objective In a recent response to a review of ABA literature, methodologies, and ethics, the authors of the response attempted to negate the compilation of research presented. The goal of their response was to advocate for the continued use of ABA and attempt to demonstrate that it is in fact effective in treating autism. The research utilized in the response does not pertain to the population discussed, does not present any neuroscientific research, and does not address intrinsic motivation, elevated levels of anxiety, or various other pertinent issues associated with the nonverbal autism population.

Methods The current paper helps clarify any misinterpretation of the original research and seeks to advocate for greater protections and ethical compliance within this vulnerable subset of individuals on the autism spectrum. Additionally, more recent research has been included to assist in this clarification.

Results Despite decades of usage as the primary method for this population worldwide, ABA has never been shown to be even slightly efficacious for the nonverbal Autism population.

Conclusions Research in ABA continues to neglect the structure the autistic brain, the overstimulation of the autistic brain, the trajectory of child development, or the complex nature of human psychology, as all of these factors were ignored in the response and are ignored in ABA practice itself. Providing a treatment that causes pain in exchange for no benefit, even if unknowingly, is tantamount to torture and violates the most basic requirement of any therapy, to do no harm.
\end{abstract}

Keywords Autism $\cdot$ Applied behavioral analysis $\cdot$ Abuse $\cdot$ Compliance $\cdot$ Autism treatment $\cdot$ Nonverbal

In its most recent biennial update, the Centers for Disease Control (CDC) indicated that approximately $31 \%$ of children with Autism Spectrum Disorder (ASD) were classified as intellectually disabled. In addition, approximately $25-50 \%$ of children with ASD do not develop functional verbal communication (Patten et al., 2013). This subset of nonverbal children with autism who are classified as intellectually disabled were the subject of the review by Sandoval-Norton and Shkedy (2019) in which they discussed the use of Applied Behavior Analysis (ABA) on this population.

As described in Sandoval-Norton and Shkedy (2019, p.1) "[ABA] is a form of behavior modification that relies heavily on external reinforcement, both positive and negative (operant conditioning). ABA is intended to modify or diminish behav-

Dalia Shkedy

dalia@altteaching.org

1 Alternative Teaching Strategy Center, San Diego, CA, USA iors, as well as increase language, communication, social skills, attention, etc., in children with ASD. The main tenets of ABA follow behaviorist theories that suggest that behavior is caused by external stimuli in the environment, which is why a reward (external) would reinforce a behavior, and punishment (external) would discourage a behavior." As ABA focuses solely on a behavior itself as opposed internal constructs (e.g., thoughts, emotions, pain) (Behavior Analyst Certification Board, 2021a, 2021b), Sandoval-Norton and Shkedy (2019) illustrated and cited research demonstrating how this can lead to psychological and physical abuse, and violates the ethical obligation to "do no harm."

Gorycki et al. (2020) published a response to SandovalNorton and Shkedy et al. (2019) in which they identified five criticisms of the original article and cited research which they alleged negates the premise of the original published article. However, the cited research does not predominantly apply to the aforementioned population and does not address the original criticism of ABA. Instead of summarizing the original review, the following is a detailed explanation and additional research to show why the original research stands. 


\section{ABA Is Unethical and Abusive}

Gorycki et al. (2020) argued against this point by discussing the Professional and Ethical Compliance Code for ABA therapists. They stated that "the ethical code mandates behaving in a way to maximize benefit and minimize harm. Practicing outside one's scope is unethical. Practicing incompetently is unethical. Instead, behavior analysts create treatment plans based on the client's needs, as dictated by the client and his/ her significant others." (Gorycki et al., 2020, p.3) The issue is not whether or not ABA therapists follow their own ethics code; the issue is the ethical scope of the practice of ABA, given that the practice of $\mathrm{ABA}$ inherently ignores all internal constructs.

Ivar Lovaas, who is revered as the father of ABA, spent the majority of his life expanding and utilizing behavior modification (Smith \& Eikeseth, 2011). All of his applications of behavior modification were consistent with the Professional and Ethical Compliance Code for ABA therapists. In the 1970s, Lovaas utilized behavior modification to treat young boys who displayed feminine characteristics. Lovaas believed these feminine "manifestations are indicative of later adult sexual abnormalities, e.g., transvestism, transsexualism, or some forms of homosexuality" (Rekers \& Lovaas, 1974, p 173). Lovaas conducted various studies attempting to change these behaviors, despite lacking a basis or understanding of what he believed were sexual abnormalities (Rekers \& Lovaas, 1974; Rekers et al., 1974; Rekers et al., 1977). Lovaas' history and involvement with the Feminine Boy Project in the 1970s is a prime example of applying behavior techniques while ignoring internal constructs. Even though the gay conversion therapy he pioneered was published and peer-reviewed, it has been condemned by many including the American Psychiatric Association (1998) and even other behavior experts Nordyke et al. (1977) and Davison (1978). As ABA is only concerned with observable and measurable outcomes, one can only begin to imagine the unobserved psychological damages caused to the subjects of these failed experiments. Clearly, the ends do not justify the means; and so ethically, there must be a prerequisite understanding of the internal processes of a human being before applying any behavior techniques to modify behavior. Following the rules of an incomplete ethics code does not make a group's behavior intrinsically ethical.

Thus, the issue at hand is threefold: (1) what behavior is inherent and appropriate, (2) what expertise is required to make such a determination, and (3) what expertise is required to recognize when the treatment is actually causing harm. In dealing with human beings, it is unethical to make an arbitrary decision on what is an appropriate behavior without understanding the long-term ramifications of attempting to change that behavior. At its core is an inherent requirement that necessitates a therapist's understanding of the internal processes and abilities of the patient before designing a treatment plan, as well as the training to recognize when the treatment is detrimental. ABA therapists are not required to take even a single class on autism, brain function, or child development (Behavior Analyst Certification Board, 2021a, 2021b). This single fact necessarily leads to at least the vast majority of ABA therapists practicing out of their scope. We are unaware of any other profession or circumstance where it is considered ethical to not study anything about the manifestation or circumstances of a condition, and then attempt to treat it. Moreover, it is negligent, dangerous, and malpractice for any professional or paraprofessional to claim expertise and implement interventions for a group they have not vigorously studied.

Furthermore, introduction to psychology academic textbooks describes the evolution of the field, and how it has moved away from the primitive understanding of human beings as being merely a bundle of behaviors (Comer, 2010; Myers \& DeWall, 2018). This is also seen in the flourishing of alternate, more developed and more scientifically supported models which incorporate cognitions, internal processes, neuroscience, genetic predispositions, multiculturalism, etc. (e.g., Beck, 1970; Deblinger et al., 2011; Dimeff \& Linehan, 2001; Linehan, 2014; Schubert et al., 1968). There would be no need for various psychological orientations if all humans were a mere bundle of behaviors who could be rewarded, punished, or conditioned into achieving anything.

Gorycki et al. (2020) stated in their response that "autism is a neurological disorder" (p.1). This statement is factual, and there is no disagreement here. However, we are compelled to point out that while the acknowledgement is proper, in theory and practice, $\mathrm{ABA}$ does not treat autism as a neurological disorder. ABA is far more concerned with outward manifestations of behavior and the treatment of those manifestations, which is a very far throw from anything that could be considered neuroscientific. Even if one was to attempt to dispute this and claim that $\mathrm{ABA}$ is concerned with neuroscience, it is notable that in courses required to become a BCBA, nothing exists that could be considered even tangential to neuroscience (Behavior Analyst Certification Board, 2012). To (correctly) claim that autism is neurological, and then proceed to ignore such a glaring obvious flaw within ABA's claim as a treatment of autism, is seriously concerning.

Gorycki et al. (2020) also defended ABA's approach to what they describe "self-stimulatory behaviors." It is unclear if they are referring to true self-regulatory behaviors or maladaptive and/or self-injurious behaviors. This is an important distinction, as research indicates that certain self-regulatory behaviors serve to regulate and calm, and as such it is vitally important to distinguish between the two types of behaviors (Baron et al., 2006; Brenner et al., 1947; Tomchek \& Dunn, 2007; Tomchek et al., 2014; Shkedy et al., 2019). Furthermore, it is therefore easily concluded that forcing a 
child to stop these soothing behaviors is largely harmful, and unhelpful. We hypothesize that the only reason that ABA attempts to "extinguish" such behaviors is, generally, to make neurotypical people more comfortable. While the behaviors may be viewed as abnormal, they help to soothe and calm the autistic person - assuming that the behavior is non-harmful, of course. Yet the practice of largescale extinguishing of all forms of undesired behavior, whether harmful or not, largely continues and persists within ABA circles. The fact that it is claimed that there are "hundreds of studies" that effectively reduce self-stimulatory behaviors that are deemed problematic by consumers, parents, and families only serves as further evidence of abuse (Gorycki et al., 2020, p. 4).

Additionally, Gorycki et al. (2020) cited that the ethical code obligates behavior analysts to refer a client who is not making progress to another professional who might be more successful. On the surface, this is laudable, but this ignores many glaringly obvious potential problems with such a practice. The client may be making progress on goals that will actually harm them in the long run. Going back and forth between "professionals" who are not trained to treat the disorder at hand is unlikely to help. This reinforces the fact that the most basic ethical requirement to practice-competency-is missing from the Professional and Ethical Compliance Code for ABA Therapists. To be clear, ABA therapists have no training, knowledge, or expertise on these behaviors within the context of the autistic brain, while at the same time purporting to be the foremost, scientifically based experts on treating autism.

Regardless, of the specific types of behaviors the authors referred to, Gorycki et al. (2020) essentially stated that ABA is successful at reducing whatever behaviors the "consumer" wants. The fact that ABA is consumer-based instead of neuroscience-based or client-centered is very problematic. We are unaware of any other healthcare profession where the patient or parent runs the treatment. Gorycki et al. (2020, p.4) stated that "if this behavior does not impede their learning and does not pose any threats to their health, then the behavior analyst is ethically obligated to discuss this with the client and parent/guardian." Firstly, ABA therapists have no training on which behaviors aid or inhibit learning and they do not have training on what behaviors might pose a threat to an autistic individual's health. (Behavior Analyst Certification Board, 2012)

Secondly, this approach makes ABA sound like a service you obtain to train a person to do or stop certain actions, regardless of the clinical implications. Today, there are still many parents who believe that boys with "female tendencies" need to be treated to "extinguish" behavior that the boy exhibits. An ABA therapist, based on all available evidence, would certainly not be trained to have that conversation with either the client or the parent, yet the scenario is not so different from what occurs in practice. We wish to remind readers that we are attempting to highlight a non-verbal, highly vulnerable population that deserves to be especially protected by the professionals serving them. Under ABA's consumerdriven model, the dignity of the child is not taken into account. The child's needs, thoughts, emotions, competence, and autonomy are notably left out of consideration in the so-called consumer-driven ABA model. These aspects of the child have been neglected likely because the people entrusted to help these children specifically have no training on how to study, understand, and treat this population, and so, they must wholly rely on the observations of parents instead of on a theoretically based, structurally sound model. The result is a mishmash of treatments and adaptions that would likely result in abuse regardless of the structural underpinnings of a treatment; this is despite the not-so-great underpinnings of ABA.

Furthermore, Gorycki et al. (2020) did not address selfinjurious behaviors in autism and the failure of the Functional Behavior Assessment (the bedrock of ABA) to address these behaviors. Shkedy et al. (2019) demonstrated that self-injurious behaviors in non-verbal children with autism are a cry for help due to their lack of communication skills; ABA therapists overwhelmingly predominantly denote these behaviors as task avoidance. It is precisely because of their lack of training in human psychology that they reach these erroneous conclusions that inevitably cause harm to their clients with autism. Furthermore, Shkedy et al. (2019) demonstrated that there is a plethora of research showing the oversensitivity the autistic brain has to external stimuli with some of them actually causing physical pain. Basic knowledge of these constraints would lead a therapist to avoid stimuli that are torturous, instead of taking on the false assumption that a child is attempting to escape or avoid a task and then continuing to expose them to the offending stimuli. This only results in a therapist forcing the non-verbal child to endure further torture.

We must emphasize that ABA therapists and associations present themselves to the government and the public as autism experts. In fact, many states in the USA have statutes declaring that an ABA therapist is an autism expert or is a qualified autism provider (e.g., Cal. Health and Safety Code 2017; Iowa Code Title IV, n.d., Human Services 2020; Minnesota, n.d., n.d.; West Virginia Code, n.d.). Representing oneself as an expert in a subject one has no knowledge of is usually considered fraud, at least once revealed. At its very core, it is the epitome of unethical action.

The growth of the neuro-diversity movement in autism is a direct result of the practice of ABA on the autism population. It was the attempt to fix "that which may not be broken" that led to this revolt. While there is no consensus in the scientific community on the validity of the neuro-diversity argument, no one has previously researched the catalyst for this outcryABA. We are not the first authors to emphasize the abusive nature of ABA therapy, and various others continue to identify 
this abuse and advocate for the termination of this abuse or for alternative treatments (Hungate, 2020; McGill and Robinson, 2020; Milton, 2020; Robinson et al., 2020; Wilkenfeld and McCarthy, 2020). Wilkenfeld and McCarthy (2020) demonstrated that ABA is unethical from a bioethics perspective. ABA violates autonomy insofar as it coercively closes off certain paths of identity formation. It also violates autonomy by coercively modifying children's patterns of behaviors to be misaligned with their preferences, passions, and pursuits.

Finally, Gorycki et al. (2020, p.4) stated that "SandovalNorton and Shkedy (2019) claimed that the practice of ABA is unethical due to the exclusive use of behavioral procedures." They then cited research to show that "students served by intensive ABA have significantly better outcomes (IQ scores, language scores, etc.) than those children who are educated with various non-ABA approaches." Firstly, the exclusive use of behavioral procedures implies ignoring all the internal processes and as shown above, is what leads to the unethical treatment. Secondly, citing research on a different population group does not validate the argument. Any study that uses IQ as a measure of improvement, as was pointed out numerous times in the original article, has excluded nonverbal children with autism since they notoriously do not have any measurable IQ. In clinical experience with hundreds of nonverbal children with autism, not one had a reported measurable IQ on any previous psychological evaluation. In addition, every public school in the USA is required to conduct a psychological exam as part of the Individualized Education Plan process. For nonverbal children with autism, the majority of those indicate that the IQ test was "attempted," "non-completed," etc. This results in non-measurable results for this population. Sandoval-Norton and Shkedy $(2019$, p.3) concluded that "There have been limited, if any, scientifically validated studies on the use of ABA on nonverbal children with ASD."

\section{ABA Promotes Prompt Dependency}

Firstly, it is important to define prompts. Prompts can be physical, verbal, visual, and even the presence of a paraprofessional can serve as a prompt. Prompting is used as a teaching technique in various fields. The goal is to discontinue prompts as the learner begins to engage in the task independently. ABA's stated long-term goal of fading prompts and improving independence are acknowledged. However, the methods utilized in ABA are fundamentally unsound for treating the severe autism population. Despite multiple decades as the most preeminent approach for treating those with severe autism, there is no research to support prompt fading actually occurring in this population. The research cited by Gorycki et al. (2020) suggesting prompt dependency is uncommon has many flaws. The studies cited to support this, involved verbal children, brief ABA interventions, and do not apply to the population and the types of interventions discussed in these authors' original publication (SandovalNorton \& Shkedy, 2019). This is likely due in part to the fact there is not very much research on this subset of autism (the main point of the original publication). Still, this population is forced to engage in these same interventions, perhaps more often than the non-severe population, despite these studies occurring without them as a primary participant. Many of them have ABA imposed on them over nearly their entire lifetime, despite the dearth of any studies focused on determining the efficacy of ABA on the severe autism population specifically.

Furthermore, research indicates prompt dependency is a very prevalent problem, even in "higher functioning" individuals (Wilson et al., 2014). Table 1 presents a sample of research on prompt dependency and attempts to reduce prompt dependency as it pertains to interventions commonly implemented in ABA. If prompt dependence was only caused by "bad" therapists, one would not expect a plethora of published research about remediating/reducing prompt dependence. The fact that this research exists implies that there is a problem. Again, the majority of research utilizes verbal or predominantly verbal individuals as there is a dearth of research on the population emphasized by Sandoval-Norton and Shkedy (2019).

\section{ABA Only Works for Children with Particular Characteristics of Autism}

Sandoval-Norton and Shkedy (2019) never stated that ABA works for children with particular characteristics, but stated that there is no research indicating that ABA works for nonverbal children with autism. Practitioners of $A B A$ and Gorycki et al. (2020) point to two meta-studies as proof that ABA is effective for treating autism (e.g., Peters-Scheffer et al., 2011; Virués-Ortega, 2010). The majority of studies in both of these meta-studies were actually discrete trial training (DTT) and the version of DTT that uses aversives (e.g., electric shocks) to punish behaviors, called the Lovaas/UCLA model. While there are ethical issues involving both of these methodologies, excluding them from the meta-studies begs the question about the efficacy of non-DTT ABA therapy as a treatment for autism. One of the consequences of the neurodiversity movement was the new wave of a "kindergentler" approach to ABA that excluded the use of DTT and the beginning of the use of Natural Environment Teaching. However, these new approaches contain no scientific support from the much quoted meta-analyses, regardless of the ethical implications of long-term ABA as discussed.

Furthermore, two major studies conducted by the US Department of Defense over a nationwide sample in the last two years massively call into question the efficacy of ABA for 
Table 1 Research on prompt dependency

\begin{tabular}{|c|c|}
\hline Reference & Aim \\
\hline Cividini-Motta (2009) & $\begin{array}{l}\text { Discusses issues with least to most and most to least prompting. Offers strategy for } \\
\text { decreasing prompt dependency. }\end{array}$ \\
\hline Fisher et al. (2007) & $\begin{array}{l}\text { Studies a hierarchy of prompting and skill acquisition in an attempt to reduce } \\
\text { prompt dependence. }\end{array}$ \\
\hline Giangreco et al. (1997) & $\begin{array}{l}\text { Proximity of a paraprofessional alone serves to suppress autonomy and } \\
\text { independence. They rely on prompt and permission from paraprofessional. }\end{array}$ \\
\hline $\begin{array}{l}\text { Gorgan and Kodak } \\
\text { (2019) }\end{array}$ & $\begin{array}{l}\text { Compared intervention skills for participants who consistently engaged in correct } \\
\text { responses following prompts, but not independently. }\end{array}$ \\
\hline Jowett et al. (2012) & $\begin{array}{l}\text { Some video-based interventions for ASD have also reported prompt dependency. } \\
\text { Embedded fading prompt in the technology helps but did not completely eradi- } \\
\text { cate. }\end{array}$ \\
\hline Karsten and Carr (2009) & $\begin{array}{l}\text { Differential reinforcement during instructional teaching procedures can have an } \\
\text { effect on the need for prompts. }\end{array}$ \\
\hline Lasley (2015) & $\begin{array}{l}\text { Discusses how to remediate prompt dependence as a result of "skill acquisition" in } \\
\text { children with Autism }\end{array}$ \\
\hline Markham et al. (2020) & $\begin{array}{l}\text { The preference for physical prompting did not match extent to which is was } \\
\text { effective. Researchers call for future research to examine prompt dependency. }\end{array}$ \\
\hline $\begin{array}{l}\text { McClannahan, and } \\
\text { Krantz (1997) }\end{array}$ & Searching for solutions to prompt dependence. \\
\hline Shabani, et al. (2002) & $\begin{array}{l}\text { Utilizing tactile prompts to initiate social interactions. Efforts to reduce prompts and } \\
\text { maintain social initiations generally unsuccessful. }\end{array}$ \\
\hline Soluaga, et al. (2008) & $\begin{array}{l}\text { Discusses efficacy of constant time delay prompting versus flexible prompt fading } \\
\text { but recognize they have not studied the prompt dependency associated with either } \\
\text { and advocate for more research in this area. }\end{array}$ \\
\hline Villegas (2016) & Attempts to decrease prompt dependence through modeling. \\
\hline Wilson et al. (2014) & Prompt dependency lasts into adulthood. \\
\hline Wilson (2020) & Discusses the cycle of prompt dependence within relationships for Autism level 1. \\
\hline
\end{tabular}

treating autism. These studies were based on real world experience and not laboratory results. In addition, the sample size for both was over 6000 , making them the largest studies these authors are aware of pertaining to autism services. The first study, presented to Congress in 2019, reported that $76 \%$ of beneficiaries had little to no change over 12 months of ABA, and $9 \%$ had worsened symptoms, as measured by ABA therapists (Stewart, 2019). The second follow-up study found no statistically significant correlation between the number of ABA hours rendered and outcome measures (Donovan, 2020). Donovan (2020) also conducted population analyses for age and severity which found that, in older children, symptoms worsened over time. Therefore, as Sandoval-Norton and Shkedy (2019) noted, the longer a child receives ABA services, the worse off they are. In sum, the largest study ever conducted on Autism found that any positive changes observed were "small and may not be clinically significant," with the vast majority of those receiving services having no change in the only thing ABA purports to treat, or even worse, regressing (Donovan, 2020, p.23). Nevertheless, ABA program spending by the Department of Defense increased by $129 \%$, from $\$ 161.5$ million in 2015 to $\$ 370.4$ million in 2019 (Donovan, 2020). It is evident what drives the recent growth of spending on $\mathrm{ABA}$ in recent years, but neither realworld efficacy nor ABA's alleged ability to help those with autism can be shown to be legitimate reasons.

While the data from the US Department of Defense did include nonverbal children with autism, research presented by Gorycki et al. (2020) and nearly all research on ABA does not pertain to this subset of autism, which, again, is the main point emphasized by Sandoval-Norton and Shkedy (2019). As mentioned above, this is because one common characteristic of this population is the inability of professionals to measure their Intellectual Quotient (IQ). As a result, any study that references IQ as a measure cannot be referring to these children as there are currently no statistically valid IQ measurements that can be used across the entire population.

Gorycki et al. (2020, p. 6) also cited that "[p]rofessionals in behavior analysis employ numerous alternative communication methods for those individuals with verbal deficits." They continue to state that "[i]n deciding which method is best, behavior analysts determine what type of communication is likely to provide the most influential impact in the shortest amount of time." While there is agreement that nonverbal children do need alternative means of communication, these comments are just more evidence of practicing outside one's 
scope. It is near impossible for a professional who is not trained in anything other than behavioral intervention to ethically make such decisions, and despite those decisions currently being made by ABA therapists, whether outside of scope or not, Gorycki et al. (2020) presented no evidence that there have been any positive outcomes as a result; this is a baseline expectation for a widely practiced method that is supposedly efficacious.

\section{ABA Includes Methodologies that Are Considered "Out of Date" and Ineffective}

The Association for Behavior Analysis International asserts that $\mathrm{ABA}$ is a natural science comparable to physics and biology (International Association for Behavior Analysis, 2019). According to the Merriam-Webster.com dictionary (2021), a natural science is one that deals with objectively measurable phenomena. While this may be true for some behaviors, there are many behaviors resulting from internal processes that are not objectively measurable. A simple example is that there is no reliable objective measure of how depressed or angry a person is, and this leads to the conflict between human psychology and ABA.

It is this lack of understanding of the human psychology and the lack of scientific rigor that leads to the malpractice of ABA. The cornerstone of ABA is the Functional Behavior Assessment (FBA), which is used to hypothesize the function of a behavior in order to treat it. Behaviorists believe that all behaviors demonstrated by all people serve a function and have a purpose. Behaviors are meant to either obtain something desirable (e.g., attention, money) or to avoid or escape something unpleasant or punishing. As a result, the most common "functions" used in a FBA are positive/negative attention, task avoidance, and escape. However, to scientifically prove a function causes a behavior, both variables need to be measurable. To prove that a child is indeed using a behavior for negative attention, both the behavior and the negative attention must be measurable. To attempt to do otherwise is conjecture and violates the requirements of a natural science. These authors are unaware of any scientifically objective measure of most of the functions ascribed in a typical FBA, especially negative attention.

Moreover, one treatment that $\mathrm{ABA}$ uses for negative attention is called extinction, where the reinforcement for the behavior is discontinued in order to attempt to decrease the incidence of the behavior. The literature on ABA lists possible side effects of extinction, one of which is depression (Powell et al., 2016). ABA therapists are not trained to recognize depression and therefore will continue this treatment while unknowingly causing psychological harm.

Gorycki et al. (2020) objected to the criticism that external reinforcement does not work in the long-term and creates psychological ill-being. They cited Cameron and Pierce (1994) to claim that external rewards do not impinge on intrinsic motivation. However, Kohn (1996) illustrated that there were failures in methodology and inclusion of evidence that led to these erroneous results. Cameron et al. (2001) made the same errors (Deci, et al., 2001). In addition, the development of motivation crowding theory from both psychology and microeconomics has added more research on the subject. Several meta-analyses have concluded that once controlling for moderating variables, motivation crowding for certain behaviors has a robust effect for certain kinds of rewards (Frey, 1997; Gneezy et al., 2011; Hossain and Li, 2014; Mellström and Johannesson, 2008; Rummel and Feinberg, 1988; Tang and Hall, 1995; Wiersma, 1992). The consensus is that crowding out reliably occurs under the following conditions: (1) rewards are offered in the context of pre-existing intrinsic motivation (for interesting tasks or prosocial settings), (2) rewards are known in advance and expected, and (3) rewards are tangible.

Besides crowding out, rewards have also been proven to have a negative effect on performance. The Yerkes-Dodson law (Yerkes and John, 1908) states that there is an optimal level of arousal for executing tasks and that departures from this level will lead to a decrement in performance. In fact, McGraw and McCullers (1979) showed that the introduction of rewards for tasks that involved problem solving had detrimental effects on performance. Ariely et al. (2005) found that increased incentives for tasks that involve creativity, problem solving, and concentration led to worse performance.

In order to ameliorate any of the symptoms associated with autism (communication, social skills and repetitive behaviors), it would require the child to perform tasks that require creativity, problem solving, and concentration. Per research, this is suppressed by external incentives, so there is no reason to believe that this amelioration occurs, and again, no legitimate proof is offered to show dampening of symptoms associated with $\mathrm{ABA}$ in those with severe autism.

\section{ABA Has No Data Showing its Effectiveness Over the Long-Term}

Once again, Gorycki et al. (2020) chose research that does not pertain to the population discussed by Sandoval-Norton and Shkedy (2019), additionally, even the research chosen does not discuss long-term use of ABA. They seem to have confused following up in the long-term with long-term use of ABA. They do not present any longitudinal studies that shows what occurs when someone receives ABA day in and day out for 5,10 , or 20 years. Nonverbal children with autism are usually given intense home-based ABA services for years, and then some, if not most of them transition to an ABAbased school program for the remainder of their school years. 
Research on the effects of prolonged, long-term use of ABA is sorely lacking.

Proponents of ABA continue to argue that their archaic approach to human behavior is suitable for the most vulnerable autistic population, though it is no longer used in the wider human population. Despite decades of usage as the primary method for this population worldwide, ABA has never been shown to be even slightly efficacious for this population. Additionally, not a single argument, response, or rebuttal has included any neuroscientific research. This is paramount and the clearest support for the fact that ABA therapists are practicing outside of their scope, and do not even attempt to educate themselves on the very foundation of autism and its associated issues. That a group of practitioners can state that "autism is a neurological disorder" at the very beginning of a paper and go on to cite zero neurological research and zero neurological basis for their claims about a supposedly efficacious treatment for autism could be considered by some as the very definition of "cognitive dissonance."

Research in ABA continues to neglect the structure of the autistic brain, the overstimulation of the autistic brain, the trajectory of child development, or the complex nature of human psychology, as all of these factors were ignored in the response and are ignored in ABA practice itself. Providing a treatment that causes pain in exchange for no benefit, even if unknowingly, is tantamount to torture and violates the most basic requirement of any therapy: to do no harm. Lastly, there is also no discussion in the response on internal motivation and how the conditions created by ABA foster psychological ill-being. If paraprofessionals and professionals refuse to engage in critical thinking, refuse to become experts at the thing they treat, continue to practice outside of scope, and continue to ignore pertinent research, the future of Autism and other conditions ABA professes to treat is very bleak.

Author Contribution GS was the primary author who designed and wrote the paper. DS collaborated on writing the paper and conducted additional research, organization and structure of the paper, and conducted literature review for recent publications on ABA. AHS collaborated on writing the paper and conducted additional research.

\section{Declarations}

Competing Interests The authors declare no competing interests.

Open Access This article is licensed under a Creative Commons Attribution 4.0 International License, which permits use, sharing, adaptation, distribution and reproduction in any medium or format, as long as you give appropriate credit to the original author(s) and the source, provide a link to the Creative Commons licence, and indicate if changes were made. The images or other third party material in this article are included in the article's Creative Commons licence, unless indicated otherwise in a credit line to the material. If material is not included in the article's Creative Commons licence and your intended use is not permitted by statutory regulation or exceeds the permitted use, you will need to obtain permission directly from the copyright holder. To view a copy of this licence, visit http://creativecommons.org/licenses/by/4.0/.

\section{References}

American Psychiatric Association (1998). Position statement on issues related to sexual orientation and gender minority status. APA Official Actions. Retrieved January 2021, from https://www. psychiatry.org/File\%20Library/About-APA/OrganizationDocuments-Policies/Policies/Position-Sexual-Orientation-GenderMinority-Status.pdf.

Ariely, D., Gneezy, U., Loewenstein, G., Mazar, N. (2005). Large stakes and big mistakes. Working Paper of the Federal Reserve. https:// www.bostonfed.org/home/publications/research-departmentworking-paper/2005/large-stakes-and-big-mistakes.aspx.

Baron, M. G., Groden, J., \& Groden, G. (2006). Stress and coping in autism. Oxford University Press.

Beck, A. T. (1970). Cognitive therapy: Nature and relation to behavior therapy. Behavior Therapy, 1(2), 184-200. https://doi.org/10.1016/ S0005-7894(70)80030-2.

Behavior Analyst Certification Board. (2012). Coursework requirements for BACB credentials. Retrieved December 2020, from https:// www.bacb.com/wpcontent/uploads/2020/05/BACB_ CourseContentAllocation.pdf.

Behavior Analyst Certification Board. (2021a). BCBA requirements. Retrieved January 2021, from https://nevadaautism.com/bcbarequirements/.

Behavior Analyst Certification Board (2021b). About behavior analysis. Retrieved February 2021, from https://www.bacb.com/aboutbehavior-analysis/.

Brenner, C., Friedman, A. P., \& Merritt, H. H. (1947). Psychiatric syndromes in patients with organic disease: 1 . Diseases of the basal ganglia. American Journal of Psychiatry, 103(6), 733-737. https:// doi.org/10.1176/ajp.103.6.733.

Cameron, J., \& Pierce, W. D. (1994). Reinforcement, reward and intrinsic motivation: A meta-analysis. Review of Educational Research, 64(3), 363-423. https://doi.org/10.3102/00346543064003363.

Cameron, J., Banko, K. M., \& Pierce, W. D. (2001). Pervasive negative effects of rewards on intrinsic motivation: The myth continues. The Behavior Analyst, 24(1), 1-44.

Cividini-Motta, C. (2009). Differential reinforcement of prompted and independent responses: An alternative procedure to decrease prompt dependency. Applied Behavioral Analysis Master's Theses, 14.

Comer, R. J. (2010). Fundamentals of abnormal psychology. Macmillan.

Davison, G. C. (1978). Not can but ought: The treatment of homosexuality. Journal of Consulting and Clinical Psychology., 46(1), 170 172. https://doi.org/10.1037/0022-006X.46.1.170.

Deblinger, E., Mannarino, A. P., Cohen, J. A., Runyon, M. K., \& Steer, R. A. (2011). Trauma-focused cognitive behavioral therapy for children: Impact of the trauma narrative and treatment length. Depression and Anxiety, 28(1), 67-75. https://oi.org/10.1002/da. 20744.

Deci, E. L., Ryan, R. M., \& Koestner, R. (2001). The pervasive negative effects of rewards on intrinsic motivation: Response to Cameron (2001). Review of Educational Research, 71(1), 43-51. https://doi. org/10.3102/00346543071001043.

Dimeff, L., \& Linehan, M. M. (2001). Dialectical behavior therapy in a nutshell. The California Psychologist, 34(3), 10-13.

Donovan, M.P. (2020). The Department of Defense Comprehensive Autism Care Demonstration Annual Report. Report to the Committees on Armed Services of the Senate and House of 
Representatives. https://altteaching.org/wp-content/uploads/2020/ 10/Annual-Report-on-Autism-Care-June-2020.pdf?x78693.

Fisher, W. W., Kodak, T., \& Moore, J. W. (2007). Embedding an identity-matching task within a prompting hierarchy to facilitate acquisition of conditional discriminations in children with autism. Journal of Applied Behavior Analysis, 40(3), 489-499. https://doi. org/10.1901/jaba.2007.40-489.

Frey, B. (1997). Not just for the money. Cheltenham: Edward Elgar Publishing.

Giangreco, M. F., Edelman, S. W., Luiselli, T. E., \& MacFarland, S. Z. (1997). Helping or hovering? Effects of instructional assistant proximity on students with disabilities. Exceptional Children, 64(1), 7 18. https://doi.org/10.1177/001440299706400101.

Gneezy, U., Meier, S., \& Rey-Biel, P. (2011). When and why incentives (don't) work to modify behavior. Journal of Economic Perspectives, 25(4), 191-210. https://doi.org/10.1257/jep.25.4.191.

Gorgan, E. M., \& Kodak, T. (2019). Comparison of interventions to treat prompt dependence for children with developmental disabilities. Journal of Applied Behavior Analysis, 52(4), 1049-1063. https:// doi.org/10.1002/jaba.638.

Gorycki, K. A., Ruppel, P. R., \& Zane, T. (2020). Is long-term ABA therapy abusive: A response to Sandoval-Norton and Shkedy. Cogent Psychology, 7(1), 1823615. https://doi.org/10.1080/ 23311908.2020.1823615.

Hossain, T., \& Li, K. K. (2014). Crowding out in the labor market: A prosocial setting is necessary. Management Science, 60(5), 1148 1160. https://doi.org/10.1287/mnsc.2013.1807.

Hungate, C. (2020). The possible harms of ABA therapy on individuals with autism [Masters Thesis, Ball State University]. Cardinal Scholar Archive. https:/cardinalscholar.bsu.edu/bitstream/handle/ 123456789/202261/HungateC 2020-2 BODY.pdf?sequence $=$ $1 \&$ isAllowed=y

International Association for Behavior Analysis. Retrieved January 2021, from https://www.abainternational.org/about-us/behavior-analysis. aspx.

Iowa Code Title IV (n.d.). Human Services [Chs. 216-255A] § 225D.1.

Jowett, E. L., Moore, D. W., \& Anderson, A. (2012). Using an iPad-based video modelling package to teach numeracy skills to a child with an autism spectrum disorder. Developmental Neurorehabilitation, 15(4), 304-312. https://doi.org/10.3109/17518423.2012.682168.

Karsten, A. M., \& Carr, J. E. (2009). The effects of differential reinforcement of unprompted responding on the skill acquisition of children with autism. Journal of Applied Behavior Analysis, 42(2), 327-334. https://doi.org/10.1901/jaba.2009.42-327.

Kohn, A. (1996). By all available means: Cameron and Pierce's defense of extrinsic motivators. Review of Educational Research, 66(1), 1-4. https://doi.org/10.3102/00346543066001001.

Lasley, J. (2015). Remediation of prompt dependence to promote independent skill acquisition for children clinically diagnosed with autism spectrum disorder [Doctoral dissertation, Nova Southeastern University]. NSU Works Archive. https://core.ac.uk/download/pdf/ 51082166.pdf.

Linehan, M. (2014). DBT? Skills training manual. Guilford Publications.

Markham, V., Giles, A., \& May, R. (2020). Evaluating efficacy and preference for prompt type during discrete-trial teaching. Behavior Modification, 44(1), 49-69. https://doi.org/10.1177/ 0145445518792245 .

McClannahan, L. E., \& Krantz, P. J. (1997). In search of solutions to prompt dependence: Teaching children with autism to use photographic activity schedules. In D. M. Baer \& E. M. Pinkston (Eds.), Environment and behavior (p. 271-278). Westview Press.

McGill, O., \& Robinson, A. (2020). 'Recalling hidden harms': Autistic experiences of childhood Applied Behavioural Analysis (ABA). Advances in Autism.

McGraw, K. O., \& McCullers, J. C. (1979). Evidence of a detrimental effect of extrinsic incentives on breaking a mental set. Journal of
Experimental Social Psychology, 15(3), 285-294. https://doi.org/ 10.1016/0022-1031(79)90039-8.

Mellström, C., \& Johannesson, M. (2008). Crowding out in blood donation: Was Titmuss right? Journal of the European Economic Association, 6(4), 845-863. https://doi.org/10.1162/jeea.2008.6.4. 845.

Merriam-Webster.com dictionary (2021). Merriam-Webster. Retrieved November 2020, from https://www.merriam-webster.com/ dictionary/natural/science.

Milton, D. (2020) Applied Behavioural Analysis and the autistic community: Time to listen. In: Are We Asking the Right Questions About Behaviour? Studio3 Web Conference, 21 Oct 2020, Online. Retrieved January 2021, from https://kar.kent.ac.uk/83599/1/ ABA\%20and\%20the\%20autistic\%20community\%2C\%20time\% 20to\%20listen.pdf

Minnesota S.F. (n.d.) NO.562 (15)(c)(1)(ii)-(iii).

Myers, D.G., \& DeWall, C. N. (2018). Psychology in modules (12th ed.). New York, NY: Worth.

Nordyke, N. S., Baer, D. M., Etzel, B. C., \& LeBlanc, J. M. (1977). Implications of the stereotyping and modification of sex role. Journal of Applied Behavior Analysis, 10(3), 553-557. https://doi. org/10.1901/jaba.1977.10-553.

Patten, E., Ausderau, K. K., Watson, L. R., \& Baranek, G. T. (2013). Sensory response patterns in nonverbal children with ASD. Autism Research and Treatment, 2013. https://doi.org/10.1155/2013/ 436286.

Peters-Scheffer, N., Didden, R., Korzilius, H., \& Sturmey, P. (2011). A meta-analytic study on the effectiveness of comprehensive ABAbased early intervention programs for children with autism spectrum disorders. Research in Autism Spectrum Disorders, 5(1), 60-69. https://doi.org/10.1016/j.rasd.2010.03.011.

Powell, R.A., Honey, P.L. \& Symbaluk, D. G. (2016). Introduction to learning and behavior. Cengage Learning.

Rekers, G. A., \& Lovaas, O. I. (1974). Behavioral treatment of deviant sex role behaviors in a male child 1. Journal of Applied Behavior Analysis, 7(2), 173-190. https://doi.org/10.1901/jaba.1974.7-173.

Rekers, G. A., Lovaas, O. I., \& Low, B. (1974). The behavioral treatment of a "transsexual" preadolescent boy. Journal of Abnormal Child Psychology, 2(2), 99-116. https://doi.org/10.1007/BF00919093.

Rekers, G. A., Bentler, P. M., Rosen, A. C., \& Lovaas, O. I. (1977). Child gender disturbances: A clinical rationale for intervention. Psychotherapy: Theory, Research \& Practice, 14(1), 2-11. https:// doi.org/10.1037/h0087487.

Robinson, A., Galbraith, I., \& Carrick, L. (2020). Practitioner experience of the impact of humanistic methods on autism practice: A preliminary study. Advances in Autism. Vol.ahead-of-print. https://doi.org/ 10.1108/AIA-05-2020-0033.

Rummel, A., \& Feinberg, R. (1988). Cognitive evaluation theory: A meta-analytic review of the literature. Social Behavior and Personality: An International Journal, 16(2), 147-164. https://doi. org/10.2224/sbp.1988.16.2.147.

Sandoval-Norton, A. H., \& Shkedy, G. (2019). How much compliance is too much compliance: Is long-term ABA therapy abuse? Cogent Psychology, 6(1). https://doi.org/10.1080/23311908.2019.1641258.

Schubert, A., McClung, M., Richards, S., Strauss, M., Carroll M., \& Backstrom, M., (1968). What is ACT? Retrieved February 10, 2021 from https://www.brightsidecounseling.net/what-is-act/.

Shabani, D. B., Katz, R. C., Wilder, D. A., Beauchamp, K., Taylor, C. R., \& Fischer, K. J. (2002). Increasing social initiations in children with autism: Effects of a tactile prompt. Journal of Applied Behavior Analysis, 35(1), 79-83. https://doi.org/10.1901/jaba.2002.35-79.

Shkedy, G., Shkedy, D., \& Sandoval-Norton, A. H. (2019). Treating selfinjurious behaviors in autism spectrum disorder. Cogent Psychology, 6(1). https://doi.org/10.1080/23311908.2019.1682766.

Smith, T., \& Eikeseth, S. (2011). O. Ivar Lovaas: Pioneer of applied behavior analysis and intervention for children with autism. 
Journal of Autism and Developmental disorders, 41(3), 375-378. https://doi.org/10.1007/s10803-010-1162-0.

Soluaga, D., Leaf, J. B., Taubman, M., McEachin, J., \& Leaf, R. (2008). A comparison of flexible prompt fading and constant time delay for five children with autism. Research in Autism Spectrum Disorders, 2(4), 753-765. https://doi.org/10.1016/j.rasd.2008.03.005.

Stewart, J. (2019). The Department of Defense Comprehensive Autism Care Demonstration Quarterly Report to Congress. https://www. altteaching.org/wp-content/uploads/2019/11/TRICARE-AutismReport.pdf?x78693.

Tang, S. H., \& Hall, V. C. (1995). The overjustification effect: A metaanalysis. Applied Cognitive Psychology, 9(5), 365-404. https://doi. org/10.1002/acp.2350090502.

Tomchek, S. D., \& Dunn, W. (2007). Sensory processing in children with and without autism: A comparative study using the short sensory profile. The American Journal of Occupational Therapy, 61(2), 190-200. https://doi.org/10.5014/ajot.61.2.190.

Tomchek, S. D., Huebner, R. A., \& Dunn, W. (2014). Patterns of sensory processing in children with an autism spectrum disorder. Research in Autism Spectrum Disorders., 8(9), 1214-1224. https://doi.org/10. 1016/j.rasd.2014.06.006.

Villegas, P. (2016). Use of video modeling to improve independent functioning skills and decrease prompt dependency in students with autism spectrum disorder [Poster Presentation]. Florida International University. https://digitalcommons.fiu.edu/sferc/ 2016/poster2016/28/.

Virués-Ortega, J. (2010). Applied behavior analytic intervention for autism in early childhood: Meta-analysis, meta-regression and dose- response meta-analysis of multiple outcomes. Clinical Psychology Review, 30(4), 387-399. https://doi.org/10.1016/j.cpr.2010.01.008.

West Virginia Code Chapter 33 (n.d.). Insurance $§ 33-25 \mathrm{~A}-8 \mathrm{j}$. Coverage for diagnosis and treatment of autism spectrum disorders.

Wiersma, U. J. (1992). The effects of extrinsic rewards in intrinsic motivation: A meta-analysis. Journal of Occupational and Organizational Psychology, 65(2), 101-114. https://doi.org/10. 1111/j.2044-8325.1992.tb00488.x.

Wilkenfeld, D. A., \& McCarthy, A. M. (2020). Ethical concerns with applied behavior analysis for autism spectrum disorder. Kennedy Institute of Ethics Journal, 30(1), 31-69. https://doi.org/10.1353/ ken.2020.0000.

Wilson, B. M. (2020). Investigating communicative dissonance within relationships of adults with Asperger's Syndrome (ASD Level 1) [Doctoral Thesis, Edith Cowan University]. Institutional Repository. https://ro.ecu.edu.au/theses/2292.

Wilson, B., Beamish, W., Hay, S., \& Attwood, T. (2014). Prompt dependency beyond childhood: Adults with Asperger's syndrome and intimate relationships. Journal of Relationships Research, 5. https://doi.org/10.1017/jrr.2014.11.

Yerkes, R. M., \& John, D. D. (1908). The relationship of strength of stimulus to rapidity of habit-formation. Journal of Comparative Neurology of Psychology, XVIII, 459-482.

Publisher's Note Springer Nature remains neutral with regard to jurisdictional claims in published maps and institutional affiliations. 